\title{
Ecobiometria ocular em bovinos mestiços Jersey x Holandês: resultados parciais
}

Naida Cristina Borges, Thais Poltronieri dos Santos, Carla Amorim Neves, Yasmim Martins Emerich Pazini, João Felipe Freire Oliveira, Wanessa Patrícia Rodrigues da Silva, Paulo José Bastos Queiroz, Leandro Arévalo Prieto, Aline Maria Vasconcelos Lima, Luiz Antônio Franco Silva

Escola de Veterinária e Zootecnia, Universidade Federal de Goiás (UFG), Goiânia, GO, Brasil

*Autor correspondente

e-mail: paulojose.vet@hotmail.com

\section{Resumo}

As dimensões das estruturas oculares se relacionam com o sexo, idade, peso, tamanho e medidas do crânio dos animais. Estas dimensões são mensuráveis por ultrassonografia, e a biometria ocular auxilia na identificação de doenças oftálmicas e sistêmicas que alteram o tamanho das câmaras. Objetivou-se descrever a anatomia ultrassonográfica ocular de bezerras mestiças (Jersey x Holandês) para a padronização da evolução biométrica do olho correlacionada com o crescimento. Os exames foram realizados em dois momentos: aos seis meses e aos 11 meses. 0 estudo foi realizado na Escola de Veterinária e Zootecnia da Universidade Federal de Goiás, após autorização do Comitê de Ética. As medidas oculares foram realizadas em corte axial horizontal e vertical, com o transdutor posicionado no centro da córnea. 0 comprimento axial (CAx), profundidade da câmara anterior (CA), espessura da lente (EL) e profundidade da câmara vítrea (CV) foram mensurados. Os dados foram submetidos à análise estatística descritiva, sendo obtidas a média das estruturas intraoculares de cada animal, que foram comparadas nos momentos avaliados. A córnea foi visualizada como duas linhas convexas, paralelas e hiperecoicas, separadas por uma fina linha anecoica. A lente apresentou-se como duas linhas hiperecoicas, sendo uma convexa (cápsula anterior) e uma côncava (cápsula posterior), separadas pelo conteúdo anecoico da lente. Adjacentes à cápsula anterior da lente foram observados a íris e o corpo ciliar, ambos de ecogenicidade moderada, sendo o corpo ciliar mais espesso e irregular comparado a outras espécies domésticas. Amplas regiões anecoicas definiram a câmara vítrea, câmaras anterior e posterior. A parede posterior do bulbo ocular apresentou-se como uma linha hiperecoica regular e côncava. Estas características ultrassonográficas foram semelhantes aos descritos para diversos mamíferos. A dimensões do CAx, EL e CV aumentaram em todos os animais com a idade, sendo tais características também descritas em seres humanos. A CA apresentou expansão apenas em quatro bezerros. A técnica empregada no exame pode ter contribuído para a redução da profundidade 
da CA em dois animais, uma vez que ocorreu maior pressão do transdutor sobre a superfície ocular. Não se pode negligenciar que o conhecimento biométrico do olho relacionado à curva de crescimento do animal é fundamental para investigações clínicas de distúrbios oculares e pesquisas em anatomia comparada. Desta forma, considerando as grandes variações raciais e de conformação craniana entre os bovinos, pondera-se que este estudo possa nortear pesquisas futuras abrangendo raças puras. 